\title{
Psychological Readiness of Primary School Teachers to the Introduction of the Inclusive education in the Republic of Dagestan
}

\author{
Saida Alirzaevna Magomedova and Angela Sergeevna Damadaeva
}

Dagestan State University, Republic of Dagestan, Mahachkala city, Gadzhiyev Street, building 43-a

DOI: http://dx.doi.org/10.13005/bbra/1938

(Received: 09 August 2015; accepted: 19 September 2015)

\begin{abstract}
This article deals with the psychological readiness of primary school teachers in the Republic of Dagestan to teaching children with special needs (psychological and physical development peculiarities) under the conditions of a regular school. The article presents the results of empirical studies that demonstrate the basic parameters of the psychological readiness of primary school teachers to include children with special educational needs into the general educational process.
\end{abstract}

Key words: inclusive education, children with special needs, psychological readiness, primary school teachers.

One of the priority directions of educational reforms in the Russian Federation is the introduction of inclusive education of children with psychophysical disabilities in a general educational institution.

Every child is special. However there are still children that are spoken of as "special" not in order to emphasize their unique abilities, but to mark those special needs that distinguish them from their peers. Quality education for these children is one of the main conditions of their successful socialization, full participation in the society. Inclusive education provides access to teaching children with special needs in general education schools through the use of the teaching methods that take into account their individual characteristics.

The introduction of inclusive education is an important factor of the society's development; it involves training for all children,

\footnotetext{
* To whom all correspondence should be addressed.
}

without exception, general education schools, as well as the creation of conditions for adjusting the educational process to the child's specific needs.

Regulatory or legislative reforms are not enough for the inclusive ideas to become a reality, proper understanding on the part of the society and teachers is necessary.

Inclusive education is a system of educational services, which is based on the principle of providing children's fundamental right to education and the right to get it locally. It involves teaching the child with special educational needs under the conditions of a general educational institution ${ }^{2,15}$.

Recently, an issue has come up. There is need for introducing changes to the system of modern education. follows:

The reasons for these changes are as

a) Improvement of the quality of psychological and educational assistance to children with psychophysical disabilities;

b) Creation of services for early detection and 
early assistance to this category of children; Organization and training of the specialists who will work in the new system;

d) Rise in births of children with various disabilities ${ }^{6}$.

At the present moment, the overall objective is to develop a concept of corrective and preventive education, aimed at the intensification of the formation process of knowledge and skills in children with special needs with the subsequent implementation of its provisions in the integral process of pre-school and school education ${ }^{7,10}$.

An ideology that excludes any discrimination against children, ensures equal treatment for all people, but creates special conditions for the children with special needs, is taken as a basis of the inclusive education. And although the "inclusion" is not a radically new phenomenon for our country, but there are many difficulties and obstacles on the way towards its effective implementation.

First of all, it comes to the professional and personal training of pedagogues to teach children with special needs. The problem of today is quite acute and requires the development of scientifically sound and practical ways to solve it.

The practice of the inclusive education introduction in Dagestan shows that school teachers, who have got accustomed to work by the well-functioning scheme, proven curricula for many years, are not ready for the new requirements, which the inclusive education puts before them, neither in a motivational, meaningful nor in a personal way.

The inclusive education, which is a part of the practice of modern school, poses a lot of complex issues and new challenges. Only with the close cooperation of all participants of the educational process, it is possible to create an inclusive educational environment, adapted to the educational needs of any child. At the same time, many experts single out socio-psychological barriers as the most important the factors that hinder the introduction of the inclusive education ideas into regular schools ${ }^{12}$.

The results of practice research show that "already at the first stages of inclusion development, the problem of regular school teachers being not ready to work with the children with special educational needs becomes quite acute, lack of teachers' professional competencies for the work in an inclusive environment is observed, pedagogues have psychological barriers and professional stereotypes" 5 .

In addition, during the implementation of integrated training, teachers face many problems, they not only need to create a common educational space, which is maximally comfortable for all students, but also provide emotional support to the parents of children with health limitations, form parents' adequate attitude to their child, cooperation set, to be able to take responsibility in the implementation process of the assistance strategy ${ }^{9}$.

The activity of parents as participants of the inclusive education process, their understanding of its essence and purpose is a necessary condition for the effectiveness of the educational process and the socialization process of children with health limitations. However, experts admit that currently the issue of parents' engagement in the inclusive educational process is developed very poorly. The low degree of parental inclusion, passive parental position "of an education service consumer" may negate the very idea of inclusive education ${ }^{11}$.

Studies, conducted in various countries, suggest a lack of teachers' awareness about the inclusion as the education system for children with psychophysical disabilities; often teachers do not know what inclusive education is and who the children with special educational needs are. For example, some teachers have the so-called dualism in their attitude to children with special needs: On the one hand, each of them sympathizes with these children and their problems, and on the other hand, when teachers face difficulties in teaching these children, they try to "isolate" them from the usual environment. However, in general, the majority of respondents-participants of the studies support the idea of co-education of healthy children and those with psychophysical disabilities ${ }^{8}$.

In addition, the fact that pedagogues have insufficient knowledge about the features of development, education and upbringing of the students with special educational needs, plays a big role. We can understand the teacher's concerns when such a child gets in their class. After all, it raises a number of issues in the organization of the educational process, its didactic and technical 
support, and adequate perception of the potential of students with psychophysical disabilities, regardless of their individual characteristics, interaction of the class team, parents and a special child himself/herself.

It is during the interaction process when the psychological readiness or unreadiness of primary school teachers to consider a child with psychophysical development deficiencies as a full member of the class group comes to the fore. Success of the student's social adaptation will ultimately depend on this readiness.

According to the researchers, the psychological readiness of teachers to introduce inclusive education includes the following components:

a) Emotional acceptance of children with psychophysical disabilities (acceptancerejection) is one of the basic psychological processes that affect the effectiveness of the teacher, who is engaged in the inclusion of a child with special needs in the education process.

b) Readiness to include children with psychophysical disabilities into class activities (inclusion-isolation);

c) Satisfaction with their own educational activity ${ }^{1}$.

Emotional acceptance has a professional "barrier" - teachers psychologically do not accept a child, in whose learning success they are not sure. They do not know how to evaluate these children's individual achievements, what method to use for checking their knowledge. In order for the process of emotional acceptance of children with psychological and physical disabilities by a pedagogue to be successful, teachers need to form empathy towards such a student. The teacher's empathy towards a student is not only one of the ways to show respect, but also an indicator of their full personal involvement in the communication, a kind of "self-improvement" in the difficult process of education and development of students. The ability to empathize not only improves the perception adequacy of the "other", but also leads to the establishment of effective, positive relationships with students. The manifestation of empathy is an emotional response from the student, and positive relationships establish between them and the teacher.
One more basic component of psychological readiness for the introduction of the inclusive education is a motivational sphere of primary school teachers, which leads to a purposeful, conscious nature of their actions and determines the individual's potential.

The inclusive approach to education is aimed at forming positive psycho-pedagogical motivation of teachers, erasing negative stereotypes and attitudes that hinder perceiving a child with special educational needs as a whole person, a full member of the society.

According to the researchers, positive motivation, mind set for success is a key to good results in any activity. School teachers, and especially primary school teachers are figures of authority for students, carriers of public opinion, under the influence of which attitudes, beliefs and future behaviour of children are formed [3].

In addition, it is an indisputable fact that the presence of teachers' positive motivation in relation to the inclusion, confidence in its compliance with contemporary social needs and its appropriateness as a means of training and education of children with psychophysical disabilities will contribute to the development of their own professional competence, and encourage to acquire new knowledge and skills.

A lot of attention is paid to this topic in the republic of Dagestan. A series of studies are devoted to the social and psychological adaptation of children with health limitations and the introduction of educational technologies into higher education institutions, dedicated to the training of future professionals for the work with such children ${ }^{4,13}$.

Thus, if teachers are not biased and do not have negative attitudes towards the child with psychophysical disabilities, if they are positive about the child's stay among healthy peers and create the conditions for a favourable social and psychological climate in the group, then it has a positive effect on the attitude of the remaining students to such a child.

And vice versa - if the pedagogue's behaviour is primarily based on negative stereotypes, and these attitudes refer to all areas of pedagogical activities - not only it prevents the adaptation of the "special" child in the class group, but also complicates, dramatically reduces the 
efficiency of the teacher himself/herself.

The same applies to the teacher's work with the parents of healthy children whose attitude to the joint education of their children together with the children with visual, hearing impairment, impairment of the locomotor system, delay in psychological development, etc. is usually not sufficiently positive and sometimes negative.

As for the personal component of pedagogues' readiness to the introduction of the inclusive education of children with psychological and physical disabilities, the results of experimental studies, which were conducted to determine the personal qualities necessary for the successful implementation of the inclusive education, suggest that surveyed teachers consider such qualities as patience, self-control, love for children, the ability to find an individual approach to the child, the ability to understand the child and the like ${ }^{14}$.

\section{Methodology}

In the context of the introduction of inclusive education ideas, a pedagogue will play a special, sometimes a new role for himself/herself, as the success of the whole educational process will depend on their ability to adapt to new requirements, the ability and desire to make their own personal, individual contribution to the implementation of the educational process, its development and improvement.

Professionally important psychological qualities play a special role in the pedagogue's readiness to the inclusive education, as the readiness for the introduction of the inclusive process in education consists not only in the presence of a new methodological material, the material base, but also in the moral and psychological readiness of the pedagogue to work with children with psychophysical disabilities.

Therefore, the goal of our study was to identify the psychological factors of primary school pedagogues' readiness to the inclusive education.

33 respondents took part in our study. They work in various educational institutions of the city of Makhachkala, capital of the Republic of Dagestan. The study group included pedagogues of the preparatory school No. 13 (11 people), as well as primary school teachers of another educational institution, which introduced the inclusive education - the State Educational Institution "Republican Centre for social and vocational adaptation and career guidance named after U.M. Murtuzalieva" of the Ministry of Education and Science of RD (RÑ SVA\&CG MES RD) (22 people).

When conducting the study the following methods were used:

a) Method for diagnosing the level of empathic abilities of V.V. Boyko, which allows determining rational, emotional, intuitive empathy channels, as well as attitudes that promote empathy, identification and penetrating power of empathy;

b) Method of PARI E. Schiffer and R. Bell is designed for studying the attitude towards different aspects of family life (family role); we were interested the most in the pedagogues' attitude to children;

c) self-actualization test (SAT), which contains the following scales: orientation in time, support, values, behaviour flexibility, sensitivity, spontaneity, self-respect, self-acceptance, ideas about human nature, synergy, aggression acceptance, rapport, cognitive needs and creativity.

Besides, we used the original questionnaire in order to examine the pedagogues' attitude to the introduction of inclusive education in the primary level of general education schools.

Statistical analysis of the research results was carried out using the Student's t-test in order to identify the differences in the attitudes of teachers of different educational institutions in relation to inclusive education.

\section{RESULTS}

Pedagogues of the RC SVA\&CG MES RD are readier than the primary school teacher of the preparatory school No.13 (gymnasium) to the inclusion introduction into the education system $(\mathrm{t}=-2.62, \mathrm{p}=0.01 ; \mathrm{t}=-3.53, \mathrm{p}=0.01)$, readier to the inclusion introduction in schools where they work $(\mathrm{t}=10.05, \mathrm{p}=0.000 ; \mathrm{t}=-3.58, \mathrm{p}=0.001)$ and to teaching children with special needs in the class with which they work $(t=4.00, p=0.000 ; t=-0.58$, $\mathrm{p}=0.56$ ).

RC SVA\&CG pedagogues' readiness to work with children with special needs is pronounced to a much greater extent (psychological: $\mathrm{t}=-3.59, \mathrm{p}=0.000$; material: $\mathrm{t}=$ 2.08, $\mathrm{p}=0.044$ and professional: $\mathrm{t}=-3.02 ; \mathrm{p}=0.004$ ). Thus, the obtained results showed that the 
teacher's direct involvement in this process influences the positive attitude towards the inclusion.

Of course, the availability of an appropriate material base in RC SVA\&CG promotes positive attitude, but the lack of contact with children with special needs of the preparatory school No.13 may cause the occurrence of negative stereotypes regarding such children and certain stigmatization.

If we take into account the problems and difficulties that may arise or are arising in the adaptation process of children with special needs in the pupils' group of an educational institution, we should mention the following milestone findings:

$70 \%$ of RC SVA\&CF pedagoguesrespondents and $60 \%$ of the No.13 preparatory school teachers-respondents note that the problem is the negative perception of children with special needs by other pupils (emotional rejection, ridicule, aggression, etc.);

$55 \%$ of RC SVA\&CF pedagoguesrespondents, $55 \%$ of the No.13 preparatory school teachers-respondents name the problem of psychological unreadiness of teachers, fear of unusual and difficult problems in the work with children who need special attention;

$60 \%$ of RC SVA\&CF pedagoguesrespondents refer to the negative attitude of the other parents to communication and joint activities of their children with a child with special needs as problematic;

$25 \%$ of RC SVA\&CF pedagoguesrespondents and $15 \%$ of the No.13 preparatory school teachers-respondents note that the problem is in the neglect of the needs and capabilities of the child on the part of administration and teachers.

Thus, in the opinion of primary school teachers, the main difficulties that may arise and are arising in the introduction process of the inclusive education are the difficulties of their own psychological qualities - unreadiness of other students, teachers and parents to the inclusion of children with special educational needs into the pupil group.

In addition, when working with pupils with special educational needs, the following problems and difficulties arise: $60.5 \%$ of teachers have problems related to the absence of special education for the work with children with special needs; $60 \%$ - lack or complete absence of special programmes and didactic material; 45\% insufficient financial incentives; $40 \%$ of teachers - heavy emotional load.

So, teachers point out that they do not have enough methodical support and additional training for the work with children with special needs, thus, the need for financial incentives is present, but does not come to the fore.

When identifying the differences in pedagogues' psychological characteristics of an inclusive education institution and a general education school, where the inclusion is not introduced, we found a difference in the mind set level for empathy - SVA\&CG pedagogues' level is higher compared to the No.13 preparatory school $(\mathrm{t}=-3.52 ; \mathrm{p}=0.00)-$ SVA\&CG pedagogues are more likely to show a deep interest in another person in a situation of interpersonal interaction and not to limit the "range" of emotional reaction.

We identified the differences in relation to different sides of family life: No. 13 preparatory school pedagogues have more of the following characteristics than the SVA\&CG pedagogues: care only about the family ( $t=2.87 ; \mathrm{p}=0.006)$, excessive care for children $(\mathrm{t}=2.12 ; \mathrm{p}=0.03)$, inhibition of aggression $(\mathrm{t}=2.65 ; \mathrm{p}=0.01)$ and child sexuality $(\mathrm{t}$ $=3.07 ; \mathrm{p}=0.003)$, desire to speed up the development of the child $(\mathrm{t}=3.12 ; \mathrm{p}=0.003)$.

Thus, pedagogues of inclusive educational institutions are more willing to accept children unconditionally, are not inclined to overly suppress their sexual and aggressive manifestations. Readiness not to overly speed up the child's development contributes to their work with children with special needs.

As for the results of the self-actualization test, we revealed higher rates among SVA\&CG pedagogues compared with the No. 13 preparatory school pedagogues by the following characteristics: orientation in time $(\mathrm{t}=-2.44 ; \mathrm{p}=$ $0.01)$, support $(\mathrm{t}=-3.07 ; \mathrm{p}=0.003)$, values $(\mathrm{t}=$ 3.43; $\mathrm{p}=0.001)$, spontaneity $(\mathrm{t}=-2.12 ; \mathrm{p}=0.04)$, self-respect $(t=-3.58 ; p=0.0009)$, cognitive needs $(\mathrm{t}=-2.26 ; \mathrm{p}=0.02)$, creativity $(\mathrm{t}=-2.37 ; \mathrm{p}=0.02)$.

Such pedagogues rely on humanistic values, which determine the desire to work with children with disabilities.

High levels of creativity among 
pedagogues of the inclusive educational institution are due to the requirements of the specifics of their work, namely search, and sometimes the development of programmes for the work with children, individual approach to each child.

To identify the links between the pedagogue's psychological characteristics and the attitude to the inclusion in the educational process of primary school, we used the Pearson's correlation coefficient.

It was found that the readiness of an elementary school teacher for the introduction of inclusive education is preconditioned to a greater extent by to the fact that he/she shares the values of self-actualization, tends to non-manipulative relationships with other people and students in particular, flexible in communication, capable of self-discovery and characterized by lack of social stereotypes. It is also important that the teacher does not avoid close communication with students and is interested in their problems and feelings.

Presence of humanistic values $(\mathrm{r}=0.33)$, a high level of empathy ( $r=0.37)$, as well as the promotion of child's verbal manifestation (verbalization) $(\mathrm{r}=0.32)$ are related to the pedagogue's readiness to children with special needs studying at a school where he or she works.

\section{DISCUSSION}

Summing up, the factors of pedagogues' attitude to inclusive education can be divided into two groups: external and internal.

The external factors include the availability of material support of educational institutions, special programmes and didactic materials as well as the pedagogues' involvement in the inclusive process, experience of working with children with special educational needs.

The internal factors - the level of pedagogue' self-actualization, their tendency to non-manipulative relationships with other people and students in particular, the flexibility in communication, the ability to self-discover and absence of social stereotypes; the level of pedagogue's empathy, as well as features of their attitude to students - to encourage verbalization, accept normal manifestations of aggression and sexuality in children and be reluctant to speed the development of children too much.
In general, the optimal formation process of the pedagogue's psychological readiness to the integration of children can be formed on the basis of inclusion of such a programme into the curriculum that would contribute to the increased interest of pedagogues to the inclusive practice, the formation of skills of independent knowledge acquisition and the application of this knowledge in the organization of work with children with health limitations; would promote tolerance, positive attitude, empathy towards children with health limitations, relieve psychological stress and form positive motivation for the work with children with special educational needs.

The conducted research allowed suggesting the following recommendations aimed at improving the effectiveness of the inclusive education introduction into primary schools.

For the education of children with psychophysical disabilities in inclusive classes of primary education schools to be successful, the teacher should acquire the necessary knowledge and skills:

1. To familiarize the student' anamnesis, have an idea of what psychological processes and functions are impaired.

2. In the process of training activities to examine the dynamics of attention, fatigue, the pace of work of each child.

3. To consider the state of hearing, vision, general and fine motor skills.

4. To learn how to adapt curricula, methods of operation and didactic materials to the individual needs of children.

5. To be able to create the optimum conditions for communication, promote the establishment of friendly relations between children, team formation.

6. To shape children's experience in the relationships in the society, adaptation skills to the social environment.

7. To prepare children in the class that students with special needs will study with them, to teach children to establish friendly relations so that children with special needs feel like members of the team.

8. Do not allow disdainful attitude towards children with disabilities.

The content, forms and methods of teaching and educational work in the inclusive classroom should have a correctional orientation. This means that each topic that children learn, each 
method must not only contribute to the acquisition of knowledge, skills and capabilities, the formation of behaviour, but must also directed at correcting the development defects (depending on the nosology).

Very important aspects in the work with these children is a well-chosen work pace, repetitiveness, in-depth individual and differentiated approach, reliance on the child's abilities, which are more developed, as well as precautions in the educational process, in order to avoid excessive load. The next component of the elementary school pedagogues' readiness to the inclusive education of children with special educational needs is the acquisition of the following personal qualities, such as: patience, self-control, love for children, the ability to find an individual approach to the child, the ability to collaborate with other specialists and use their advice, kindness, benevolence, ability to understand the child and the like. Therefore, successful and efficient practical implementation of inclusive education primarily depends on the attitude of a pedagogue as a subject of training activities.

If features of the child's psychophysical development are almost always a constant factor, the ability of teachers to consciously change their attitude to such children, expand knowledge and skills in training and education of children with psychophysical disabilities, use a variety of forms, methods and ways of working can change for the better. It is under these conditions the introduction of inclusion into practice of general education institutions can be effective. Persons with impaired development require not only compassion, but also help to become full members of the society, to be able to fully socialize in our present.

Very important aspects in the work with these children is a well-chosen work pace, repetitiveness, in-depth individual and differentiated approach, reliance on the child's abilities, which are more developed, as well as precautions in the educational process, in order to avoid excessive load.

We can give the following advice to the teachers, working in inclusive classrooms with children with special needs:

a) Remember that children, who have impaired psychophysical development, need psychological support from the teacher more than anybody else;

b) Praise the child, use feedback, react to their little achievements emotionally, increases self-esteem, status in the team;

c) Children with impaired psychophysical development need a light training mode, but it does not mean reduced insistence on the assimilation of the programme material, it is a corresponding organization of the learning mode;

d) Assignments and instructions that are addressed to all students of the class should be worked out in detail for such a child, so that the tasks become accessible for the understanding and implementation;

e) Adaptation of training material to the needs of the student is necessary;

f) Form positive motivation in training;

g) Find various opportunities for a student's performances before the class; bring him/ her to the group activities so that he/she does not feel unwanted and useless in the class collective;

h) During work rely on the student's strengths, mark his/her achievements, especially in activities in which he/she is interested;

i) Constantly encourage students to use the correct ways to point out mistakes;

j) Under all circumstances stick to the tactics of tolerant behaviour;

k) Communicate and collaborate with the student's parents closely and as often as possible.

\section{CONCLUSION}

A pedagogue is the most important link in the organization of inclusive education.

To work with the children with special educational needs, it is necessary to carry out a diagnostics of possibilities and needs of the child, to give their expert assessment and to develop an individual educational programme on this basis, renounce collective methods.

To do this, a teacher should have a deep knowledge of their subject, teaching techniques, as well as methods of working with children with special psychophysical development.

A large number of pedagogues are 
experiencing difficulties, because they do not possess such knowledge, do not have experience in a team, and do not use the knowledge and experience of colleagues, parents in the organization of the educational process of persons with special educational needs.

Therefore, it is very important to prepare teachers for such work, provide them with knowledge of the special and social pedagogy, present tools and models of alternative education.

Addressing the psychological and pedagogical readiness of pedagoguespsychologists to work with children with health limitations will enable the intensive introduction of inclusive education in the country; increase the level of professional competence of graduates, i.e. will satisfy all consumers of educational services - individuals, society, state.

Therefore, successful and efficient practical implementation of the inclusive education process primarily depends on the attitude of a pedagogue, as a subject of training activities, to it.

\section{REFERENCES}

1. Alekhina, S.V., Alekseeva, M.A., \& Agafonova, E.L., Readiness of Teachers as a Key Success Factor in the Process of Inclusive Education. Psychological Science and Education, 2011; 1L 83-92.

2. Bryzgalova, S.O., \& Zak, G.G., The Inclusive Approach and Integrated Education of Children with Special Educational Needs. Special education, 2010; 3: 14-20.

3. Valitskaya, A.P., \& Rabosh, V.A., Inclusive Education - Education for All. Social Pedagogy, 2009; 1: 18-22.

4. Magomedova, S.A., Magdieva, N.T., Musayeva, S.D., Damadaeva, A.S., \& Mameeva, D.M., Capabilities of the Department of Social Medicine as a Training Centre for Specialists in the Field of Medical and Social Work. In The Forms and Methods of Social Work in Various Spheres of Life: Proceedings of the Second International Scientific and Practical Conference 2013; 223-224. Retrieved August 28, 2015, from http://elibrary.ru/item.asp?id=23735603.
5. Gluhova, E. S., \& Litvina S.A., Psychological Readiness Problems of the Educational Process Participants to the Introduction of Inclusive Education. Psychology of Education, 2013; 1: 28-39.

6. Golikov, N., Individual Child-Person with Disabilities Care under the Condition of Education in a Regular Educational Institution. Teacher, 2006; 1: 22-24.

7. Grigorieva, M. A., The Integration of Children with Health Limitations in General Education Space. Special Education, 2009; 4: 98-102.

8. Denisova, O.A., Ponikarova, V.N., \& Lekhanova, O.L., The Strategy and Tactics of the Preparation of Pedagogues for the Inclusive Education. Defectology, 2012; 3: 81-89.

9. Zadorin, I.V., Kolesnikova, E.Y., \& Novikova, E. Ì., Inclusive Education in Moscow: Differentiation of Participants' Knowledge as a Limiting Factor. Psychological Science and Education, 2011; 1: 60-71.

10. Kizima, A., \& Esikova, E., Integration of Children with Disabilities in a Regular School: Overcoming Psychological Barriers and Features of Education and Upbringing. Principal, 2008; 3: 68-73.

11. Loshakova, I.I., \& Yarskaya-Smirnova, E.P., Integration in the Conditions of Differentiation: Problems of the Inclusive Education of Children with Disabilities. In Social and Psychological Education Problems of Atypical Children 2002; 15-21. Saratov: Publishing house of the Pedagogical Institute of the Saratov State University.

12. Malantseva, O., Co-education of Healthy Children and Children with Special Needs. Social Pedagogy, 2008; 2: 63-67.

13. Shakhov, S.K., Aliyev, T.G, \& Damadaeva, A.S., Features of the Socio-Psychological Adaptation of Adolescents with Asthma. News of the Dagestan State Pedagogical University. Psychological and Pedagogical Sciences, 2012; 3(20): 29-34.

14. Sorokoumova, S.N., Psychological Characteristics of Inclusive Education. Proceedings of the Samara Scientific Centre of the Russian Academy of Sciences, 2010; 3: 1012.

15. Rijswijk, S. (Ed.)., Special Education in the Development. Saint-Petersburg, 1996. 